Jurnal Tarbawi| Volume 2|No 1| ISSN 2527-4082| 71

\title{
PLURALISME AGAMA DALAM PANDANGAN AL-QURAN DAN IMPLEMENTASI PENDIDIKAN ISLAM
}

\author{
Alamsyah ${ }^{1}$ \\ ${ }^{* 1}$ Pendidikan Agama Islam Fakultas Agama Islam| Unismuh Makassar
}

\begin{abstract}
ABSTRAK
Sikap Al Qur'an terhadap Pluralitas agama begitu jelas dan merupakan sunnatullah. Pluralisme agama merupakan kenyataan historis yang tidak dapat disangkal oleh siapapun. Pluralitas agama dalam Islam itu diterima sebagai kenyataan sejarah yang sesungguhnya diwarnai oleh adanya pluralitas kehidupan manusia itu sendiri, baik pluralitas dalam berpikir, berperasaan, bertempat tinggal maupun dalam bertindak. Oleh karena itu konsep pluralisme agama menurut Al-Quran apakah dapat di implementasikan dalam pendidikan Islam. Penelitian ini dikaji dalam bentuk kajian Pustaka (Librari riserch) dengan metode kualitatif dengan pendekatan Tafsir tematik. Di dalam Al-Quran bayak ayat yang membenarkan tentang pluralitas Agama namun Pluralisme Agama tidak dibenarkan karena pemahaman Pluralisme Agama menurut orang Orientalis adalah semua agama itu sama, namun konsep Al-Qur'an Pluralitas adalah membenarkan adanya agama yang lain tetapi konsep kebenaran menurut Al-Qur'an Agama yang paling benar adalah Islam. Namun implementasi pendidikan Islam menurut Al-Qur'an, islam mengajarkan konsep Ukhuwah Islamiyah, dimana didalamnnya ada Ukhuwah Al- U'budiyah dan Ukhuwah Al-Insaniyah yaitu persaudaraan sesama Makhluk dan persaudaraan sesama manusia.
\end{abstract}

\section{Kata Kunci: Pluralisme, Al-quran dan Implementasi Pendidikan Islam}

\begin{abstract}
The attitude of the Qur'an to the Plurality of religion is so clear and is the sunnatullah. Religious pluralism is a historical reality that no one can deny. The plurality of religions in Islam is accepted as a historical reality which is actually colored by the plurality of human life itself, whether plurality in thinking, feeling, living or acting. Therefore, the concept of religious pluralism according to the Quran can be implemented in Islamic education. This research is studied in the form of literature review (Librarian research) with qualitative method with thematic Tafsir approach. In the Qur'aan there is a verse that justifies the plurality of Religion but Religious Pluralism is not justified because the understanding of Religious Pluralism according to the Orientalists is all the same religion, but the concept of Al-Qur'an Plurality is to justify the existence of another religion but the concept of truth according to Al-Qur'an The most true religion is Islam. But the implementation of Islamic education according to Al-Qur'an, Islam teaches the concept of Ukhuwah Islamiyah, where therein Ukhuwah Al-U'budiyah and Ukhuwah Al-Insaniyah are the brotherhood of fellow Beings and brotherhood of fellow human beings.
\end{abstract}

Keywords: Pluralism, Al-Quran and Implementation of Islamic Education 


\section{PENDAHULUAN}

Kerusuhan-kerusuhan yang terjadi pada akhir-akhir ini di berbagai daerah di Indonesia, seperti kasus Situbondo (1998), Selain itu yang masih bergejolak sampai saat ini seperti kasus Poso, dan beberapa pemboman di Bali yang menewaskan banyak orang, bukan hanya itu dalam alam kemerdekaan Islam dan Kristen terdapat beberapa ketegangan dari berbagai kasus sebagaimana ditulis pendeta Jan S. Aritonang dalam Sejarah perjumpaan Islam dan Kristen din Indonesia (2006), Islam dan Kristen terlibat dalam perdebatan yang sangat serius dalam perumusan undang-undang Perkawinan, undang-undang pendidkian nasional 1989 dan 2003, masalah pendirian tempat ibadah dan penyebaran agama serta masalah-masalah lainnya, pada dasarnya merupakan akibat dari konflik antar agama yang berbeda. Masing-masing pihak mengklaim bahwa dirinyalah yang palin benar, sedangkan pihak lain salah.

Akibat dari perseteruan tersebut adalah kesengsaraan semua pihak, yang bertikai maupun yang tidak mengetahui apa-apa. Pada dasarnya akibat dari konflik adalah kerugian diberbagai pihak. Rakyat kecil lagi-lagi menjadi korban dan harus menanggung akibatakibat yang ditimbulkan oleh konflik tersebut.

Sentimen keagamaan dan fanatisme membuat paling tidak banyak memberi andil atas terciptanya setiap adegan kerusuhan dan terjadinya konflik. Konflik yang mengatas namakan agama pada umumnya disebabkan oleh penyimpangan arah proses sosial yang berkolerasi logis dengan bentuk-bentuk menyimpang interaksi sosial antar umat beragama.

Dari fenomena-fenomena terse-but setidaknya dapat dijadikan fonis awal bahwa sampai saat ini, kesadaran pluralitas dalam beragama belum menyentuh sisi kesadaran paling dalam pada diri para pemeluk agama. Artinya, slogan-slogan bahwa agama mengajarkan cinta kasih dan perdamaian, tidak menyukai tindakan kejahatan dalam bentuk apapun hanyalah sebatas konsep yang belum terealisasi secara menyeluruh.

Di sinilah paling tidak, perlu diperhatikan kembali tentang peran pendidikan Islam bagi umat Islam itu sendiri. Islam sebagai "rohmatan lil 'alamin" sudah dapatkah diwujudkan, karena posisi umat Islam sebagai mayoritas di satu sisi sangatlah tidak menguntungkan, dan ironisnya ternyata umat Islam dapat dikatakan hampir banyak ikut serta dalam setiap aksi kerusuhan. Mengapa bisa terjadi demikian ? tentunya ada yang salah. Atau bisa jadi pendidikan Islam belum mampu mendidik umatnya menjadi kaum pluralis ? ini perlu dikaji kembali sebagai upaya perbaikan mutu pendidikan Islam itu sendiri. 
Berdasarkan uraian di atas di atas, maka dalam penelitian ini akan membahas tentang pluralisme Agama dalam pandangan Al-Quran tentang, dan implementasi pendidikan Islam menurut Al-Quran.

\section{METODE PENELITIAN}

$\begin{array}{llr}\text { Jenis } & \text { penelitian ini adalah } \\ \text { penelitian } & \text { yang bersifat kajian } \\ \text { kepustakaan } & \text { (Library Researce) yang } \\ \text { difokuskan } & \text { pada penelusuran dan }\end{array}$
penelaan literature serta bahan pustaka yang dianggap ada kaitannya dengan fenomena pluralisme agama. Adapun pendekatan yang digunakan adalah pendekatan Tafsir Maudu'i.

Sumber data dalam penelitian ini ada dua yaitu data primer dan data sekunder. Data primer adalah berupa buku-buku yang secara khusus membahas tentang pluralisme agama dan pendidikan Islam. Sedangkan Data sekunder adalah referensi atau bukubuku yang dapat mendukung permasalahan pokok yang dibahas.

Teknik pengelolaaan data yaitu data yang dihimpun melalui riset kepustakaan semua data bersifat kualitif, yaitu pengungkapan data melalui deskripsi (pemaparan), sehingga dalam pengelolaannya yaitu mengadakan dan mengemukakan sifat data yang diperoleh kemudian dianalisa lebih lanjut guna mendapatkan kesimpulan.
Lebih lajut penulis akan melakukan analisis data. pada tahap ini, ada tiga tahap yang dilalui dalam penelitian ini, yaitu: reduksi data (data reduction), penyajian data (data display), dan penarikan kesimpulan (conclusion drawing).

\section{HASIL PENELITIAN DAN PEMBAHASAN}

Pluralisme adalah hal yang harus benar-benar dapat dimaknai sesuai dengan akar kata serta makna sebenarnya. Hal itu merupakan upaya penyatuan persepsi untuk menyamakan pokok bahasan sehingga tidak akan terjadi salah pengertian maupun salah pemahaman.

Pertama, bertolak dari akar kata yang pertama yaitu pluralisme. Kata pluralisme berasal dari bahasa Inggris yang berakar dari kata "plural" yang berarti banyak atau majemuk. Sedangkan dalam Kamus Ilmiah Populer, pluralisme berarti: Teori yang mengatakan bahwa realitas terdiri dari banyak substansi.

Akar kata yang kedua adalah agama, yang berasal dari kata "ugama" dalam bahasa Sansekerta yang berarti aturan-aturan. Dalam al-Qur'an, agama biasa dilambangkan dengan kata "diin". M. Quraish Shihab, dalam Membumikan Al-qur'an mengatakan bahwa, agama adalah satu kata yang sangat mudah diucapkan dan mudah untuk 
memberikan penjelasan maksudnya (khususnya bagi orang awam), tetapi sangat sulit memberikan batasan (definisi) yang tepat lebih-lebih bagi para pakar.

Pendidikan merupakan usaha dapat mengembangkan potensi dirinya melalui proses pembelajaran atau cara lain yang dikenal dan diakui oleh masyarakat. Islam menurut makna katanya, adalah sikap pasrah dan tunduk kepada tuhan yang maha Esa. Orang yang tunduk dan patuh terhadap Tuhan Yang Maha Esa disebut dengan Muslim, bentuk jamaknya disebut "muslimin". Dalam kepasraan terkandung keyakinan bahwa hanya Tuhanlah hanya satu-satunya yang harus disembah, dipuji dan diagungkan, dalam ajaran ini dalam islam disebut Tauhid.

Menurut Menurut Langgulung (1997: 54) pendidikan Islam tercakup dalam delapan pengertian, yaitu AtTarbiyyah Ad-Din (Pendidikan keagamaan), At-Ta'lim fil Islamy (pengajaran keislaman), Tarbiyyah AlMuslimin (Pendidikan orang-orang islam), At-tarbiyyah fil Islam (Pendidikan dalam islam), At-Tarbiyyah 'inda Muslimin (pendidikan dikalangan Orang-orang Islam), dan At-Tarbiyyah Al-Islamiyyah (Pendidikan Islami).

Dari beberapa defenisi diatas dapat dapat diambil kesimpulan bahwah pendidikan islam adalah suatu proses transfer ilmu pengetahuan yang berkaitan dengan ajaran-ajaran agama islam.

\section{A. Pluralisme Agama Dalam Persfektif Al-Qur'an}

Ada sebuah fenomena menarik di tengah pluralnya masyarakat. Hubungan antar umat beragama saling menghargai dan rukun. Namun kerukunan tersebut menjadi hancur berantakan karena adanya "clash" antar umat beragama yang terjadi di daerah tersebut. Mengakibatkan adanya kerukunan semu tanpa dilandasi kesadaran hidup bermasyarakat secara plural.

Sikap Al-Qur'an terhadap Pluralitas Agama begitu jelas dan merupakan Sunnatullah. Pluralisme agama dalam Islam itu diterima sebagai kenyataan sejarah yang sesungguhnya diwarnai oleh adanya pluralitas kehidupan manusia itu sendiri, baik Pluralitas dalam berpikir, berperasaan, bertempat tinggal maupun dalam bertindak.

Al-Qur'an dalam memberikan pendidikan kesadaran terhadap Pluralisme agama terhadap umat manusia diantaranya tampak dari sikapsikapnya sebagai berikut :

\section{Mengakui eksistensi agama lain.}

Dalam Qs. An Nahl : 93 "Dan kalau Allah menghendaki, niscaya dia menjadikan kamu satu umat (saja), tetapi Allah menyesatkan siapa yang dikehendaki-Nya dan memberi 
petunjuk kepada siapa yang dikehendaki-Nya. (Depag. RI.2013 :277)

Menurut Qurais Shihab (2002:710711) memang dalam dunia ini banyak kelompok yang berbeda-beda atau bertolak belakang tetapi itu adalah kehendak Allah. Seandainya dia menghendaki, dia akan menjadikan kamu seia sekata, tetapi itu tidak dikehendakinya dan dia akan memutuskan perbedaan itu kelak diakhirat bukan di dunia ini. Jadi jangan jadikan perbedaan sebagai dalih tidak menepati janji walaupun dengan kelompok yang berbeda Aqidah dan kepercayaan dengan kamu. Dan jikalau Allah menghendaki namun tidak tidak dikehendakinya, Niscaya dia menjadikan kamu satu umat saja.

\section{Memberinya hak untuk hidup berdampingan saling menghormati pemeluk agama lain.}

Dalam Qs.Al.An'am: 108 megatakan "Dan janganlah kamu memaki sembahan-sembahan yang mereka sembah selain Allah, Karena mereka nanti akan memaki Allah dengan melampaui batas tanpa pengetahuan..." (Depag.RI.2013:141)

Ayat ini ditujukan kepada kaum Muslimin yakni, dan janganlah kamu wahai kaum muslimin memaki sembahan-sembahan, seperti berhalaberhala yang meraka sembah selain Allah karena jika kamu memekainya, maka akibatnya mereka akan memaki pula Allah dengan melampaui batas atau secara tergesah-gesah tanpa berfikir dan tanpa pengetahuan.

Menghindari kekerasan dan memelihara tempat-tempat beribadah umat beragama lain Qs. Al.Hajj : 40. Dalam tafsir Al Maraghi Al Hajj : 40, Ahmad Mustofa Al Marghi menyebutkan Allah menampilkan dua golongan yang berselisih, menentukan objek perselisihannya dan menjelaskan kesudahan masing-masing dari dua golongan tersebut, berupa kehinaan dan kemuliaan, adzab dan kenikmatan.

Ayat tersebut diatas oleh sebagian ulama, seperti Al-Qurthubi (Qurais Sihab:380), mengatakan ayat di atas dijadikan sebagai argumentasi keharusan umat Islam memelihara tempat-tempat Ibadah non Muslim. Al-Qur'an tidak akan pernah mentolelir perusakanperusakan rumah Ibadah umat beragama lain, karena tindakan yang demikian dampaknya akan menimpa umat itu sendiri dengan adanya balasan dari pihak lain. Ujung-ujungnya akan menjadi sarana balas dendam yang tidak berkesudahan.

\section{Larangan adanya unsur paksaan}

Al-Qur'an tidak pernah membenarkan adanya paksaan dalam memeluk suatu agama karena itu berkaitan erat dengan hak-hak manusia yang perlu mendapatkan penghargaan setelah disampaikan pesan-pesan (message) al-Qur'an yang 
sesungguhnya. Ayat al-Qur'an, surah alBaqarah ayat 256 menyebutkan:

"Tidak ada paksaan untuk (memasuki) agama (Islam); Sesungguhnya Telah jelas jalan yang benar daripada jalan yang sesat...." (Depag. RI.2013:42)

Qurais Shihab (2002: 668-671) mejelaskan lebih lanjut ayat di atas,

Tidak ada paksaan dalam menganut agama, Allah tidak membutuhkan sesuatu dari manusia jadi tidak usah ada paksaan. Sekiranya Allah menghendaki maka Allah akan jadikan hanya satu kaum saja. Tetapai yang dimaksud dengan tidak ada paksaan adalah dalam menganut agama dan keyakinan. Ini berarti jika seseorang telah menganut satu agama misalnya agam Islam, maka dia terikat dengan tuntunannya dia berkewajiban melaksanakan perintah-perintahnya. Dan terancam sangsi ketika dia melakukan pelanggaran

\section{B. Implementasi pendidikan Islam Menurut Al-Qu'ran}

Islam adalah agama yang mengajarkan tentang cinta kedamaian dengan konsep Ukhuawah Islamiyah, sehingga terjadi kerukunan dalam bermasyarakat. Islam adalah agama yang diturungkan oleh Allah kepada Nabi Muhammad.

Sedangkan menurut Himpunan Putusan Tarjih Muhammdiyah (2001:278) agama yakni agama Islam adalah agama yang dibawah oleh Nabi Muhammad Saw ialah apa yang diturungkan didalam Al-Qur'an dan yang tersebut dalam Sunnah yang Shahih berupa perintah-perintah, dan larangan-larangan serta petunjuk di dunia dan diakhirat. Agama adalah apa yang disyariatkan Allah dengan perantara Nabi-nabinya berupa perintahperintah dan larangan-larangan serta petunjuk-petunjuk untuk kebaikan manusia di Dunia dan di Akhirat.

Dari pengertian di atas sudah jelas bahwah implementasi yang akan dimaksud adalah ajara-ajaran yang ada dalam Al-Qur'an dan Sunnahnya Nabi. Oleh karena itu Islam mengajarkan kita:

\section{Ajakan berbuat damai}

Islam dengan konsep cinta damainya mengjarkan kita untuk hidup rukun baik sesema umat Islam maupun non Islam. salah satu Firman Allah Qs. Al.Hajj:40

"(yaitu) orang-orang yang Telah diusir dari kampung halaman mereka tanpa alasan yang benar, kecuali Karena mereka berkata: "Tuhan kami hanyalah Allah". dan sekiranya Allah tiada menolak (keganasan) sebagian manusia dengan sebagian yang lain, tentulah Telah dirobohkan biara-biara Nasrani, gereja-gereja, rumah-rumah ibadat orang Yahudi dan masjid- masjid, yang di dalamnya banyak disebut nama Allah. Sesungguhnya Allah pasti menolong orang yang menolong 
(agama)-Nya. Sesungguhnya Allah benar-benar Maha Kuat lagi Maha Perkasa. (Depag. RI.2013:337).

Al-Qur'an, seperti yang termaktub dalam ayat di atas jelas tidak menghendaki adanya perseteruan antar agama. Dengan adanya agama sebagai pedoman hidup hendaknya menjadikan seseorang sebagai sosok yang gandrung dengan kedamaian dan cinta kasih. Bukan sebaliknya sebagai jiwa perusak, seperti fenomena umat beragama saat ini yang gemar melakukan perusakan tempat ibadah umat beragama lain.

Namun menurut Prof. Dr. Hamka (1983:278) mengatakan;

Bagi umat Islam yang hidup dizaman pergolakan segalah agama ini sehingga ada fikiran-fikiran hendak mepersatukan segalah agama, ayat ini adalah pokok dakwah yang utama. Da'I dan Muballigh Islam hendaklah sanggup membawa manusia kepada kesatuan pegangan agama dengan mengemukakan ayat ini. Inilah ayat dakwah yang wajib dijadikan pokok, yang membawa kepada titik-titik pertemuan.

Jadi Islam mengajarkan kedamaian dengan berbagai macam Agama namun Islam tidak membenarkan mempersatukan, dalam artian membenarkan semua agama itu sama. Karena Islam mengajarkan Tauhid yaitu mengesakan Allah swt. ayat diatas menurut Hamka adalah ayat dakwah untuk mengajak kaum kafir untuk masuk Islam kejalan yang benar tapi tidak ada paksaan didalamnya.

\section{Larangan adanya unsur paksaan}

Al-Qur'an tidak pernah membenarkan adanya paksaan dalam memeluk suatu agama karena itu berkaitan erat dengan hak-hak manusia yang perlu mendapatkan penghargaan setelah disampaikan pesan-pesan (message) al-Qur'an yang sesungguhnya.

Oleh karena itu konsep Jihad dengan mengebom yang dilakukan oleh oknum yang megaku Islam itu tidak dibenarkan yang ada adalah Al-Qur'an hanya membenarkan adanya peringatan (mengingatkan), dalam surat alGhasyiah : 21-24. Setelah peringatanperingatan itu disampaikan dan ternyata tidak mau juga merambah jalan yang menuju kebenaran, maka keyakinan dan ritual-ritual yang mereka jalani menjadi urusan masing-masing dan tidak boleh ada perasaan permusuhan karena tertolaknya ajakan (surat al-Kaafirun).

\section{Konsep Ukhuwah Islamiyyah}

Ukhuwah sering diartikan sebagai sebuah bentuk atau hubungan persaudaraan antara seseorang dengan orang lainnya. Yang paling besar gaungnya adalah tentang Ukhuwah Islamiyah. Ukhuwah yang biasa diartikan sebagai "persaudaraan", menurut M. Quraish Shihab (1996:31), terambil dari akar kata yang pada mulanya berarti "memperhatikan". Maka 
asal ini memberi kesan bahwa persaudaraan mengharuskan adanya perhatian semua pihak yang merasa bersaudara.

Menurut Sihab (1996:32) konsep tentang "Ukhuwah Islamiyah" dibahas secara panjang lebar oleh M. Quraish Shihab. Menurutnya, istilah "Ukhuwah Islamiyah" ini perlu didudukkan maknanya, agar bahasan tentang "ukhuwah" tidak mengalami kerancuan. Untuk itu terlebih dahulu perlu dilakukan tinjauan kebahasaan untuk menetapkan kedudukan katan "Islamiyah" dalam istilah di atas. Selama ini ada kesan bahwa istilah tersebut bermakna "persaudaraan yang dijalin oleh sesama muslim", atau dengan kata lain, "persaudaraan antar sesama muslim", sehingga dengan demikian, kata "Islamiyah" dijadikan pelaku Ukhuwah itu.

Pemahaman ini kurang tepat. Kata "Islamiyah" yang dirangkaikan dengan kata Ukhuwah lebih tepat dipahami sebagai "adjektifa", sehingga "ukhuwah islamiyah" berarti "persaudaraan yang bersifat Islami atau yang diajarkan oleh Islam”. (Shihab, 1996: 486-487).

Berkaitan dengan ukhuwah islamiyah, Muhammadiyah Sul-sel(112113).: Al-Qur'an memperkenalkan paling tidak empat macam persaudaraan

a. Ukhuwah di al-'ubudiyyah, yaitu bahwa seluruh makhluk adalah bersaudara dalam arti memiliki kesamaan (Qs. Al-An'am(6): 38).
Persamaan ini antara lain, dalam ciptaan dan ketundukan kepada Allah dan kesamaan dan proses penyembahan cuman berbeda caranya.

b. Ukhuwah fi al-insaniyah, dalam arti keseluruhan umat manusia adalah bersaudara, karena mereka bersumber dari ayah dan ibu yang satu. Ayat Al-Hujurat 12 menjelaskan tentang hal ini.rasul saw. Juga menekankannya dalam sabda beliau: "Kuиnuu 'ibadallah ikhwanaa al- 'ibad kulluhumikhwat'.

c. Ukhuwah fi al-wathaniyah wa alnasab. Persaudaraan dalam keturunan dan kebangsaan seperti yang disyaratkan oleh ayat wa ila 'ad akhahum hud, dan lain-lain.

d. Ukhuwah fi din al-Islam. Persaudaraan antar sesama muslim, seperti bunyi surah al-Ahzab 5 dan Surah Alhujurat Ayat 11. demikian juga dalam sabda Rasulullah saw.: "Kalian adalah sahabat-sahabatku, saudara-saudara kita adalah yang datang sesudah [wafat]-ku”.

Lebih lanjut M. Quraish Shihab dalam (1995: 359) menyatakan bahwa faktor penunjang lahirnya persaudaraan dalam arti luas ataupun sempit adalah persamaan. Semakin banyak persamaan semakin kokoh pula persaudaraan. Persaudaraan dalam rasa dan cinta merupakan faktor yang sangat dominan yang mendahului lahirnya persaudaraan hakiki dan yang pada akhirnya 
menjadikan seorang saudara merasakan derita saudaranya. Sebagai contoh adalah mengulurkan tangan bantuan kepada saudaranya sebelum diminta serta memperlakukannya bukan atas dasar take and give tetapi justru "Mengutamakan orang lain walau dirinya sendiri kekurangan".(Q.S. 59: 9).

Dari fenomena yang dipaparkan di atas paling tidak sudah begitu mencukupi sebagai bukti bahwa AlQur'an benar-benar menghargai adanya pluralitas, sesuai pembahasan kali ini. Itu menunjukkan betapa Al-Qur'an berisi penuh ajaran-ajaran kasih dan sayang. Tidak seperti yang dituduhkan para orientalis sementara ini.

\section{KESIMPULAN}

Dari uraian tentang konsep AlQur'an tentang pluralisme agama dan implementasinya dalam pendidikan Islam dalam bab-bab terdahulu, dapat diambil kesimpulan sebagai berikut:

1. Pluralisme adalah paham yang membenarkan yang namanya kemajemukan, keberagaman, dan kesetaraan dari segalah aspek. Islam mengajarkan cinta kasih dan kedamain sehingga Pluralitas dan pluralis sangat dijungjung tinggi sebagai salah satu proses menjalangkan perintah Allah tentang hidup rukun dan menjaga tatanan kehidupan sehingga tidak terjadi konflik yang diakibatkan ketegangan antar agama karena menganggap masing-masing benar, Tetapi harus dibingkai dengan toleransi beragama.

2. Pendidikan Islam saat ini sangat mengedepangkan konsep Ukhuwah Islamiyah yang disebut dengan Ukhuwa Al-Ubudiyah yaitu persaudaraan sesama Makhluk.

\section{DAFTAR PUSTAKA}

Al-Maliky, Syaikh Ahmad Al-Shawy, Hasyiah Al-'Allamah Al-Shawy 'Ala Tafsir AI-Jalalain,: Dar Ihya' Al-Kutub Al-Arabiyah, tt. Surabaya.

Ali, Atabik dan Ahmad Zuhdi Muhdlor, Al-'Ashriy. $1996 \quad$ Kamus Kontemporer Arab-Indonesia,. Yayasan Ali Maksum,. Yogyakarta.

Hamka,2003.Tafsir Al Azhar. Cet. 2003. Pustaka Panjimas:Jakarta

Husain, Muchtar. 2002. Pandangan Islam terhadap Permasalahan Sosoal. Cet. I. UII PRESS : Yogyakarta

,Muhammadiyah, 2011.Himpunan Putusan Tarjih,Cet. 3. Suara Muhammadiyah:Yogyakarta

Mu'ti, Abdul. Ul haq, Fajar Riza. 2009. KRISTEN DAN MUHAMMADIYAH: onvergensi Muslim dan Kristen dalam Pendidikan. Cet. I. Al Wasat Pulishing Hause : Jakarta 
Muhammadiyah Sulsel, PW.2012.Materi Dakwah Ramadhan.Cet I:P3i Pers:Makassar.

Musdaqi, Irwan. 2011. Berislam Secara Toleran. Cet. I. PT. Mizan Pustaka:Bandung.

Muhammad, Husain. 2011. Mengaji Pluralisme. Cet. I. Al. Mizan: Bandung

Manaf, Mujahid Abdul. 1994. Ilmu Perbandingan agama. Cet. I. PT raja Brafindo Persada: Jakarta

Muhammad,jalaluddin. Tafsir Al Imamu Jalalain Toha Putra: Semarang

Mustofa maroghi,ahmad: 2006. Tafsir Almaroghi.Cet. 2. Dar Al kotob Al Ilmiyah: libanon

Nizar, Syamsul. 2008. SEJARAH PENDIDIKAN ISLAM: Menelusuri Jejak Sejarah Pendidikan Era Rosulullah Sampai Indonesia. Cet. II. Fajar Interpratan Offset. : Jakarta

Prasetyo, Stanley. 2001. Pluralisme Dan dialog Keadilan.Cet. I. Institud DIAN/ Interfidel:Ryo

Rahman, Budhy Munawar. 2010. Sekularisme, Liberalisme, Dan Pluralisme. PT Erasindo:Jakarta

Rahman, jalaluddin. 2003. Psikologi Agama Sebuah Pengantar. Cet. I. PT. Mizan Pustaka: Bandung

Shihab, M. Quraish. 2007. MEMBUMIKAN AL-QUR'AN: Mukjizat Al-Qur'an. Cet. I. PT Mizan Pustaka: Bandung
,1995. Membumikan Al-Qur'an,: cet. XII. Mizan; Bandung , 1996. Wawasan Al-Qur'an, : Cet. III,. Mizan,: Bandung ,2011, Tafsir Al-Misbah.Cet. IV.penerbit Lentera hati:Jakarta Zahairini, DKK. 2010. Sejarah Pendidikan Islam. Cet. 10. PT Bumi Aksara : Jakarta 